\title{
Occupational class differences in outcomes after ischemic stroke: a prospective observational study
}

\author{
Yinwei Zhu ${ }^{1+}$, Yaling Lư ${ }^{1 \dagger}$, Mo Zhou², Ping Huang ${ }^{3}$, Peipei Zhang ${ }^{4}$, Yumei Guo ${ }^{5}$, Liying Lv ${ }^{5}$, Yonghong Zhang ${ }^{1}$, \\ Chongke Zhong ${ }^{1^{*}}$ and Tan $\mathrm{Xu}^{1^{*}}$
}

\begin{abstract}
Background: Occupational class is an integral part of socioeconomic status. The studies focused on the occupational difference in ischemic stroke outcome in a Chinese population are limited. We aimed to investigate the associations between occupational class and the prognosis of patients with ischemic stroke in China.

Methods: We included 1484 ischemic stroke participants (mean age: $63.42 \pm 11.26$ years) from the prospective cohort study: Infectious Factors, Inflammatory Markers and Prognosis of Acute Ischemic Stroke (IIPAIS). Occupational class was categorized into white-collar workers, blue-collar workers and farmers in our study. Study outcomes were cardiovascular events and all-cause mortality within 12 months after ischemic stroke onset. We applied Cox proportional hazard model to evaluate the associations between the occupational class and study outcomes after ischemic stroke.

Results: Within 12 months after ischemic stroke, there were 106 (7.5\%) cardiovascular events and 69 (4.9\%) all-cause deaths. The Kaplan-Meier plots showed that white-collar workers had highest risk of cardiovascular events after 12month follow-up (Log-rank $P=0.02$ ). Multivariate adjusted hazard ratio and 95\% confidence intervals (Cls) of farmers versus white-collar workers was $0.43(0.20-0.91)$ for cardiovascular events. No significant difference showed in bluecollar workers versus white-collar workers, with fully adjusted hazard ratio $0.62(95 \%$ Cls, 0.23-1.67).

Conclusions: Compared with white-collar workers, farmers are associated with less risk of cardiovascular events at 12 months after ischemic stroke, while there are no significant differences in blue-collar workers.
\end{abstract}

Keywords: Occupation, Ischemic stroke, Cardiovascular events, White-collar worker, Farmer, Prognosis

\section{Background}

Stroke is the second leading cause of disability adjusted life years in the old around the world [1]. According to the data from National Epidemiological Survey of Stroke in China 2013, the age-specific prevalence of stroke

\footnotetext{
* Correspondence: ckzhong@suda.edu.cn; xutan@suda.edu.cn

${ }^{\dagger}$ Yinwei Zhu and Yaling Lu contributed equally to this work.

'Department of Epidemiology, School of Public Health and Jiangsu Key Laboratory of Preventive and Translational Medicine for Geriatric Diseases, Medical College of Soochow University, 199 Renai Road, Industrial Park District, Suzhou, Jiangsu Province 215123, People's Republic of China Full list of author information is available at the end of the article
}

increased with age, especially in those aged $\geq 50$ years [2]. In China, individuals with ischemic stroke have a relatively poor prognosis after first stroke, with major vascular event rate of $27 \%$ at 1 year and $45 \%$ at 5 years [3]. China is facing severe challenges to the disease burden from stroke. Socioeconomic status, typically including income, education, employment and social status, is widely believed to have link with the incidence and outcomes of the stroke [4,5]. Pierre Amarenco et found that low levels of socioeconomic status are associated with vascular events and ischemic stroke [6, 7]. Making

(c) The Author(s). 2021 Open Access This article is licensed under a Creative Commons Attribution 4.0 International License, which permits use, sharing, adaptation, distribution and reproduction in any medium or format, as long as you give appropriate credit to the original author(s) and the source, provide a link to the Creative Commons licence, and indicate if changes were made. The images or other third party material in this article are included in the article's Creative Commons licence, unless indicated otherwise in a credit line to the material. If material is not included in the article's Creative Commons licence and your intended use is not permitted by statutory regulation or exceeds the permitted use, you will need to obtain permission directly from the copyright holder. To view a copy of this licence, visit http://creativecommons.org/licenses/by/4.0/ The Creative Commons Public Domain Dedication waiver (http://creativecommons.org/publicdomain/zero/1.0/) applies to the data made available in this article, unless otherwise stated in a credit line to the data. 
sense of the influence of socioeconomic factors on outcomes of stroke has valuable public health significance for improving stroke prognosis.

The occupation often means the work in which individuals serve the community and serve as a major source of livelihood. The occupational experiences have profound effects on physical and mental health by some means. On the one hand, a job can offer both intellectually and socially enriched environment, supporting cognitive function. On the other hand, job is one of the main sources of stress among employees. Emerging studies had revealed that various kinds of stress at work have been related to poorer cognitive ability $[8,9]$.

As a well-known indicator of socioeconomic status, occupational class is considered to be a key factor of the development of cardiovascular diseases. There are varying backgrounds, prospects and outcomes in different occupations, and these are not given across or even within occupations [10]. Thus, there exists health difference among various occupational populations. For instance, those with low occupational status often have high prevalence of risk factors, such as low quality of care and limited access to high-quality medical resource [11]. Previous studies reported that white collars have more risk suffering from poor prognostic factors of stroke, like diabetes and hypertension [12, 13]. However, the findings on the associations between occupational status and stroke prognosis are not consistent. Several findings reported that low occupation increased risk of stroke mortality $[14,15]$, while others showed no significant associations [16, 17].

Knowledge of disparities in outcomes after stroke is of great importance for effective stroke management and prognosis improvement. Yet, occupation status differs in clinical and lifestyle factors and many of the existing studies were aimed to examine occupational disparities in single outcome of stroke $[15,18]$. Moreover, the studies focused on the associations of occupation class with outcomes of stroke in Chinese population were scarce. Therefore, we investigated the association between occupational class and cardiovascular events and all-cause mortality after stroke onset among white-collar, bluecollar workers and farmers in China.

\section{Materials and methods}

\section{Study design and population}

The multicenter prospective cohort study Infectious Factors, Inflammatory Markers and Prognosis of Acute Ischemic Stroke (IIPAIS) was designed to evaluate the associations of infectious factors and inflammatory markers with clinical outcomes of ischemic stroke [19]. It recruited a total of 1711 patients aged $\geq 40$ years with first-ever ischemic stroke from June 2011 to December 2013 in 25 hospitals of five provinces (Jilin, Liaoning,
Jiangsu, Hebei and Henan) and two autonomous regions (Inner Mongolia and Ningxia) across China. All included ischemic stroke patients were confirmed by computed tomography or magnetic resonance imaging of the brain within $72 \mathrm{~h}$ of symptom onset. Furthermore, the IIPAIS excluded patients with subarachnoid hemorrhage, transient ischemic attack, cerebral hemorrhage, or hemorrhage caused by tumor or hematologic diseases, along with pregnant women. The present study was a secondary analysis of IIPAIS, which was designed to find the associations between occupation class and ischemic stroke prognosis. For the present study, a total of 1484 ischemic patients were included, excluding 40 patients (2.3\%) who lost 1-year follow-up and 187 patients whose occupation information could not accord with the inclusion criteria of the study.

IIPAIS was approved by the institutional review boards at Tulane University in the United States and Soochow University in China. All patients engaged in the research provided written informed consents.

\section{Data collection}

We used a standard questionnaire to collect baseline data with respect to demographic characteristics, medical history and clinical features at the time of enrollment. Trained neurologists applied the National Institutes of Health Stroke Scale (NIHSS) at baseline to assess the stroke severity. Trial of Org 10,172 in Acute Stroke Treatment (TOAST) criteria was used to classify the ischemic stroke subtypes as large-artery atherosclerosis (thrombotic), cardiac embolism (embolic), smallvessel occlusion (lacunar), stroke of other determined etiologies, and stroke of undetermined etiology, according to the symptoms and imaging data of the patients by experienced neurologists [20]. The blood pressure (BP) was measured by trained nurses when the patient was in the supine position, according to a standard protocol adapted from procedures recommended by the American Heart Association [21]. At admission, all participants took routine serologic tests (fasting plasma glucose, blood lipids, creatinine, etc.) in corresponding participating hospital.

\section{Occupation class}

Study participants self-reported their longest-held occupations, whose classification was based on Labor Law of the People's Republic of China. According to the existing researches [22, 23], we classified occupation into three groups: white-collar workers including office workers, managers and professional technician; blue-collar workers including technicians and machine operators; and farmers. Homemakers and freelance were excluded because of limited quantity. 


\section{Assessment of outcomes}

Participants were followed up in person for 12 months after onset or hospital discharge by trained neurologists who were unaware of treatment assignment. In the analysis, the outcomes were defined as cardiovascular events and all-cause mortality. Cardiovascular events included recurrent stroke, myocardial infarction, heart failure, pulmonary embolism and peripheral arterial disease, which were abstracted from related hospital. The causes and date of death were verified by examining hospital medical records. The outcome assessment committee reviewed and adjudicated vascular events based on the criteria established in the Antihypertensive and LipidLowering Treatment to Prevent Heart Attack Trial (ALLHAT) [19].

\section{Statistical analysis}

All participants were divided into 3 subgroups according to self-reported occupation. Basic characteristics of the study population were described by means with standard deviation (SD), median with interquartile range (IQR) or frequencies with percentages, which were compared between the 3 groups, using the variance analysis or the $x^{2}$ test, as appropriate.

We calculated the incidence density to describe the study outcomes in different groups. The Kaplan-Meier curve was applied to compare the different prognosis among the groups with log-rank test. To further investigate the association between occupation and ischemic stroke prognosis, Cox proportional hazard model was used to calculate hazard ratios (HRs) and 95\% confidence intervals (CIs) for the associations of occupational class with the stroke prognosis. The white-collar group served as the reference group for the analyses. We performed 3 Cox proportional hazard models. Model 1 was an unadjusted model. Model 2 only adjusted for age, sex. Model 3 included the factors in model 2 as well as current cigarette smoking, current alcohol drinking, time from stroke onset to hospitalization, ischemic stroke subtype, baseline NIHSS score, diastolic blood pressure, high-density lipoprotein cholesterol, fasting plasma glucose, medical history (hypertension, hyperlipidemia, coronary heart disease, diabetes mellitus, family history of stroke), treatment during hospitalization (hypoglycemic, anticoagulants, antiplatelet agents, thrombolysis), NIHSS score at discharge, education, urban and employed.

In addition, subgroup analysis was performed to test whether the associations between occupational class (white-collars and farmers) and ischemic stroke prognosis was modified by age, sex, education, race, urban, current cigarette smoking, current alcohol drinking, baseline NIHSS score and history of hypertension. Multiple imputation for missing data was performed using the Markov chain Monten Carlo method. All $P$ values were two tailed, and $\mathrm{P}$ values $<0.05$ were considered to be statistically significant. Statistical analysis was conducted using the SAS, version 9.4 (SAS Institute) and R, version 4.0.3 (R Foundation).

\section{Results \\ Baseline characteristics}

A total of 1484 patients (mean age, $63.42 \pm 11.26$ years; $67.99 \%$ male) were enrolled and classified in this analysis, containing white-collar $(n=369)$, blue-collar $(n=$ $559)$ and farmer $(n=596)$. Table 1 presents the baseline characteristics of participants according to occupational class. Between three groups, the distribution of some characteristics significantly differed $(P<0.001)$, such as age, sex, education, residence, employment, baseline $\mathrm{Na}$ tional Institutes of Health Stroke Scale score, history of hyperlipidemia and history of diabetes mellitus. However, no significant difference was observed in this analysis between groups in terms of current cigarette smoking, current alcohol drinking, time from stroke onset to hospitalization, systolic BP, total cholesterol, family history of stroke and history of infection before onset.

\section{Association between occupation class and ischemic stroke prognosis}

There were 106 (7.5\%) cardiovascular events and 69 (4.9\%) all-cause deaths during one year of follow-up (Table 2). From white-collar to blue-collar and farmer group, the incidence densities of cardiovascular events were 113.15 (PYs/1000), 83.47(PYs/1000) and 56.82(PYs/ 1000), respectively. Generally, Kaplan-Meier plots showed that white-collar workers had highest risk of cardiovascular events after 12-month follow-up (Log-rank $P=0.02$; Fig. 1).

In the unadjusted Cox proportional hazard model (model 1), compared with white-collar workers, farmers had fewer cardiovascular events (HR 0.50, 95\% CI 0.310.82), while there was no significant difference in bluecollar workers (HR in cardiovascular events $0.74,95 \% \mathrm{CI}$ 0.47-1.15) (Table 2). After additional adjustment for current cigarette smoking, current alcohol drinking, time from stroke onset to hospitalization, ischemic stroke subtype, baseline NIHSS score, diastolic blood pressure, high-density lipoprotein cholesterol, fasting plasma glucose, medical history (hypertension, hyperlipidemia, coronary heart disease, diabetes mellitus, family history of stroke), treatment during hospitalization (hypoglycemic, anticoagulants, antiplatelet agents, thrombolysis), NIHSS score at discharge, education, urban and employed (model 3), the adjusted HRs for the blue-collar class and the farmer class were $0.66(95 \% \mathrm{CI}, 0.41-1.06)$ and 0.43 (95\% CI, 0.20-0.91) for cardiovascular events, compared with the white-collar class, respectively. 
Table 1 Characteristics of 1484 ischemic stroke patients in IIPAIS

\begin{tabular}{|c|c|c|c|c|c|}
\hline Characteristics* & Total (1484) & White-collar (369) & Blue-collar (559) & Farmer (556) & $P$ value \\
\hline \multicolumn{6}{|l|}{ Demographic } \\
\hline Age,y & $63.42 \pm 11.26$ & $64.69 \pm 11.91$ & $64.19 \pm 10.98$ & $61.81 \pm 10.92$ & $<0.001$ \\
\hline Men & $1009(67.99)$ & $277(75.07)$ & 399 (71.38) & $333(59.89)$ & $<0.001$ \\
\hline \multicolumn{6}{|l|}{ Education } \\
\hline |lliteracy & $115(7.75)$ & $12(3.25)$ & $26(4.65)$ & $77(13.85)$ & $<0.001$ \\
\hline Primary & $490(33.02)$ & $43(11.65)$ & $127(22.72)$ & $320(57.55)$ & $<0.001$ \\
\hline Middle & $726(48.92)$ & 199 (53.93) & $374(66.91)$ & $153(27.52)$ & $<0.001$ \\
\hline College & $153(10.31)$ & $115(31.17)$ & $32(5.72)$ & $6(1.08)$ & $<0.001$ \\
\hline Current cigarette smoking & $592(39.89)$ & $140(37.94)$ & $227(40.61)$ & $225(40.47)$ & 0.676 \\
\hline Current alcohol drinking & $508(34.23)$ & $135(36.59)$ & $176(31.48)$ & $197(35.43)$ & 0.208 \\
\hline Urban & $905(60.98)$ & $337(91.33)$ & $504(90.16)$ & $64(11.51)$ & $<0.001$ \\
\hline Employed & $343(23.11)$ & $120(32.52)$ & $127(22.72)$ & $96(17.27)$ & $<0.001$ \\
\hline \multicolumn{6}{|l|}{ Clinical features } \\
\hline Time from stroke onset to hospitalization, h & & & & & 0.889 \\
\hline $0-24$ & $1210(81.54)$ & $304(82.38)$ & $454(81.22)$ & $452(81.29)$ & \\
\hline $24-72$ & $274(18.46)$ & $65(17.62)$ & 105 (18.78) & $104(18.71)$ & \\
\hline Systolic BP (mmHg) & $149.29 \pm 21.09$ & $148.36 \pm 20.16$ & $148.69 \pm 21.56$ & $150.52 \pm 21.19$ & 0.217 \\
\hline Diastolic BP (mmHg) & $88.53 \pm 12.59$ & $87.32 \pm 12.06$ & $87.84 \pm 13.04$ & $90.02 \pm 12.35$ & 0.002 \\
\hline Heart rate (bpm) & $74.81 \pm 10.55$ & $75.31 \pm 10.31$ & $74.64 \pm 10.92$ & $74.65 \pm 10.34$ & 0.579 \\
\hline Baseline NIHSS score & $5.00(3.00-8.00)$ & $5.00(3.00-8.00)$ & $4.00(2.00-7.00)$ & $5.00(3.00-9.50)$ & $<0.001$ \\
\hline NIHSS score at discharge & $3.00(1.00-6.00)$ & $3.00(1.00-5.00)$ & $3.00(1.00-5.00)$ & $3.00(2.00-7.00)$ & 0.011 \\
\hline \multicolumn{6}{|l|}{ Ischemic stroke subtype } \\
\hline Thrombotic & $688(54.69)$ & $180(55.73)$ & $247(52.55)$ & $261(56.13)$ & 0.498 \\
\hline Embolic & $69(4.65)$ & $17(4.61)$ & $27(4.83)$ & $25(4.50)$ & 0.018 \\
\hline Lacunar & $525(41.73)$ & $129(39.94)$ & $201(42.77)$ & $195(41.94)$ & 0.725 \\
\hline \multicolumn{6}{|l|}{ Serological examination } \\
\hline FPG $(\mathrm{mmol} / \mathrm{L})$ & $5.70(5.05-7.22)$ & $6.00(5.20-7.50)$ & $5.70(5.01-7.47)$ & $5.60(4.98-6.90)$ & 0.001 \\
\hline Total cholesterol (mmol/L) & $4.98(4.24-5.80)$ & $5.00(4.26-5.62)$ & $4.89(4.23-5.78)$ & $5.06(4.24-5.86)$ & 0.473 \\
\hline Triglycerides (mmol/L) & $1.47(1.08-2.09)$ & $1.54(1.08-2.18)$ & $1.42(1.03-2.10)$ & $1.47(1.11-1.96)$ & 0.298 \\
\hline $\mathrm{LDL}(\mathrm{mmol} / \mathrm{L})$ & $3.20(2.55-3.79)$ & $3.20(2.61-3.82)$ & $3.20(2.59-3.79)$ & $3.16(2.51-3.77)$ & 0.586 \\
\hline $\mathrm{HDL}(\mathrm{mmol} / \mathrm{L})$ & $1.19(0.98-1.43)$ & $1.15(0.93-1.36)$ & $1.15(0.98-1.41)$ & $1.24(1.04-1.50)$ & $<0.001$ \\
\hline \multicolumn{6}{|l|}{ Disease history } \\
\hline Hypertension & $901(60.71)$ & $245(66.40)$ & $340(60.82)$ & $316(56.83)$ & 0.014 \\
\hline Hyperlipidemia & $165(11.12)$ & $63(17.07)$ & $62(11.09)$ & $40(7.19)$ & $<0.001$ \\
\hline Coronary heart disease & $229(15.43)$ & $70(18.97)$ & $98(17.53)$ & $61(10.97)$ & 0.001 \\
\hline Diabetes mellitus & $292(19.68)$ & $103(27.91)$ & $123(22.00)$ & $66(11.87)$ & $<0.001$ \\
\hline Family history of stroke & $365(24.60)$ & $107(29.00)$ & $129(23.08)$ & $129(23.20)$ & 0.077 \\
\hline \multicolumn{6}{|l|}{ Treatment during hospitalization } \\
\hline Anticoagulants & $339(22.84)$ & $81(21.95)$ & $126(22.54)$ & $132(23.74)$ & 0.799 \\
\hline Antiplatelet agents & $1431(96.43)$ & $356(96.48)$ & $536(95.89)$ & $539(96.94)$ & 0.635 \\
\hline Thrombolysis & $59(3.98)$ & $17(4.61)$ & $14(2.50)$ & $28(5.04)$ & 0.075 \\
\hline Antihypertensive & $729(49.12)$ & $195(52.85)$ & $253(45.26)$ & $281(50.54)$ & 0.054 \\
\hline Glucose-lowering agents & $275(18.53)$ & $92(24.93)$ & $108(19.32)$ & 75 (13.49) & $<0.001$ \\
\hline
\end{tabular}

Abbreviations: IIPAIS Infectious Factors, Inflammatory Markers, and Prognosis of Acute Ischemic Stroke; BP blood pressure; NIHSS National Institute of Health Stroke Scale; $H D L$ high-density lipoprotein; $L D L$ low-density lipoprotein; $F P G$ fasting plasma glucose

* Continuous variables are expressed as mean \pm standard deviation or median (interquartile range). Categorical variables are expressed as frequency (\%) 
Table 2 Association with occupational class and prognosis during 12-month follow-up

\begin{tabular}{|c|c|c|c|c|c|}
\hline & \multirow{2}{*}{$\begin{array}{l}\text { White- } \\
\text { collar } \\
\text { (reference) }\end{array}$} & \multicolumn{2}{|l|}{ Blue-collar } & \multicolumn{2}{|l|}{ Farmer } \\
\hline & & $\mathrm{HR}(95 \% \mathrm{Cl})$ & $P$ value & $\mathrm{HR}(95 \% \mathrm{Cl})$ & $P$ value \\
\hline \multicolumn{6}{|l|}{ Cardiovascular events } \\
\hline Cases,n(\%) & $37(10.03)$ & $41(7.33)$ & & $28(5.04)$ & \\
\hline Cases/PYs(/1000) & 113.15 & 83.47 & & 56.82 & \\
\hline Model 1 & 1.00 & $0.74(0.47-1.15)$ & 0.176 & $0.50(0.31-0.82)$ & 0.006 \\
\hline Model 2 & 1.00 & $0.74(0.48-1.16)$ & 0.190 & $0.54(0.33-0.88)$ & 0.015 \\
\hline Model 3 & 1.00 & $0.66(0.41-1.06)$ & 0.086 & $0.43(0.20-0.91)$ & 0.028 \\
\hline \multicolumn{6}{|l|}{ All-cause mortality } \\
\hline Cases,n(\%) & $20(5.80)$ & $24(4.71)$ & & $25(5.03)$ & \\
\hline Cases/PYs(/1000) & 57.94 & 46.31 & & 49.06 & \\
\hline Model 1 & 1.00 & $0.80(0.44-1.44)$ & 0.454 & $0.81(0.45-1.46)$ & 0.480 \\
\hline Model 2 & 1.00 & $0.82(0.45-1.49)$ & 0.511 & $1.00(0.55-1.83)$ & 0.999 \\
\hline Model 3 & 1.00 & $0.65(0.34-1.25)$ & 0.198 & $0.62(0.23-1.67)$ & 0.347 \\
\hline
\end{tabular}

Abbreviations: $H R$ hazard ratio; $C l$ confidence interval; $P Y$ person year

Model 1: adjusted for age and sex;

Model 2: adjusted for model 1 and further adjusted for current cigarette smoking, current alcohol drinking, time from stroke onset to hospitalization, ischemic stroke subtype, baseline NIHSS score, diastolic blood pressure, high-density lipoprotein cholesterol, fasting plasma glucose, medical history (hypertension, hyperlipidemia, coronary heart disease, diabetes mellitus, family history of stroke), treatment during hospitalization (hypoglycemic, anticoagulants, antiplatelet agents, thrombolysis), NIHSS score at discharge, education, urban and employed

\section{Subgroup analysis}

In the subgroup analysis, the results in age subgroup were consistent. While other covariates, including gender, residence, baseline NIHSS score, current cigarette smoking, current drinking and history of hypertension, to some extent, modified the association between occupational class and cardiovascular events outcome (Fig. 2).

\section{Discussion}

Despite occupational class was considered to be a potential fundamental social factor for cardiovascular disease risk, little was known about the associations between the occupational class and the posttreatment conditions of stroke [11]. In this prospective study, we observed that compared with white-collar patients, patients working as a farmer had a lower risk of cardiovascular events within 12 months after stroke, after adjustment for several traditional stroke risk factors. However, we found no systematic differences in the association between occupational class and all-cause mortality.

Generally, previous evidence on the relationship between occupational class and incidence of stroke is inconsistent. McFadden and colleagues demonstrated that higher social class was associated with decreased incidence of stroke in UK, both in men and women [24]. Moreover, in a matched hospital case-control study in Japan, including 41,038 stroke patients, managers/professionals had lower stroke risk than the blue-collar [25]. Within a population-based stroke registry, low socioeconomic status in any life stage is associated with an increased risk of stroke [26]. While other studies implied that low occupational status had a significantly lower risk of stroke. In a cohort study in Sweden, older men with the lowest occupational status,like unskilled manual, had a significantly lower risk of ischemic stroke [27]. $\mathrm{Xu} \mathrm{F}$ et found a significantly elevated OR of stroke prevalence in white collar workers compared to blue collar workers, after adjustment for traditional risk factors [22]. However, these studies focused on the incidence of stroke rather than the poor outcomes, and they, to some extent, had insufficient adjustment for confounders.

The occupation groups have relatively distinct social and environmental conditions of work, including occupational physical activities, work schedule demands and work stress, which could partly explain the difference between the occupational groups [28, 29]. The reasons for the difference could be attributed to the difference in work environment, social background, life style and so on. In a large prospective study in China, which enrolled 487,334 study participants, higher level of occupational physical activity was associated with lower risks of major vascular events in adults [30]. Similarly, previous studies found that sitting occupation and sedentary behavior are linked to an increased risk of stroke [31, 32]. In a French population-based cohort, exposure of long working hours for 10 years or more could increase the risk of stroke [33]. Several studies have found that pre-existing poor mental health has a significant impact on longterm stroke outcome [34, 35]. Furthermore, psychological stress at work, which differs in occupation categories, is associated with poor mental health and can 

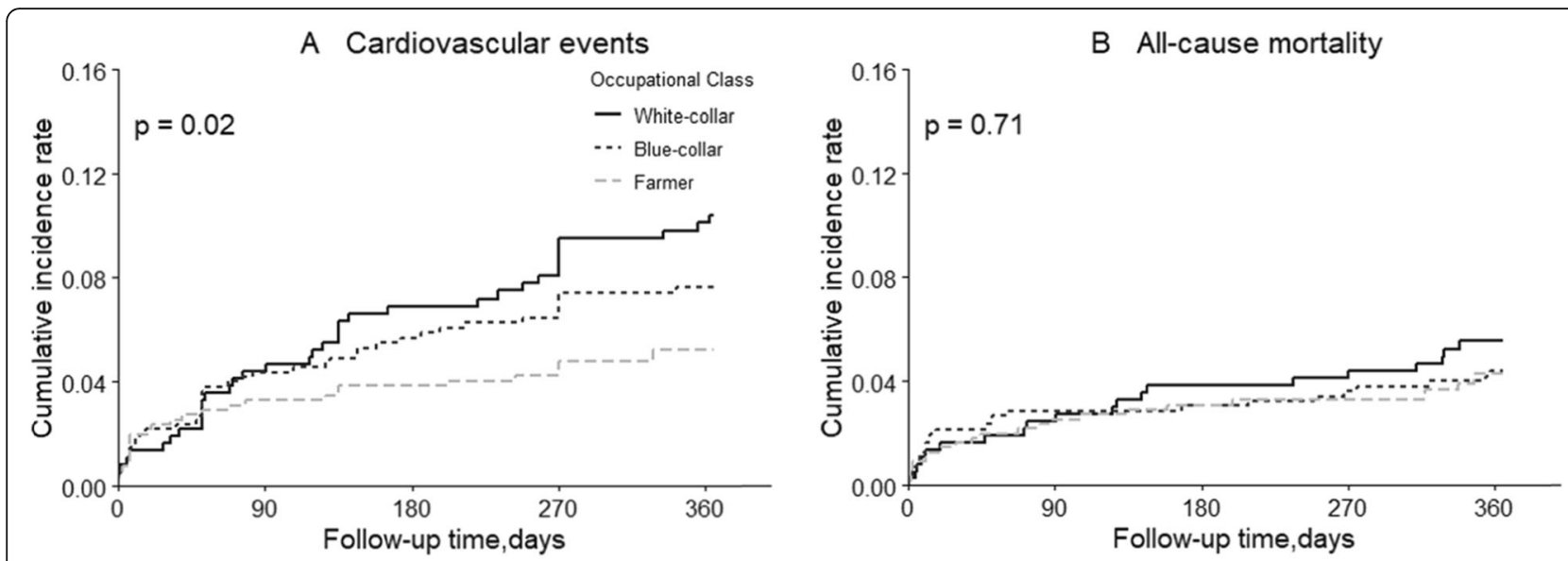

Fig. 1 Kaplan-Meier survival curves of cardiovascular events (A) and all-cause mortality (B) according to occupational class

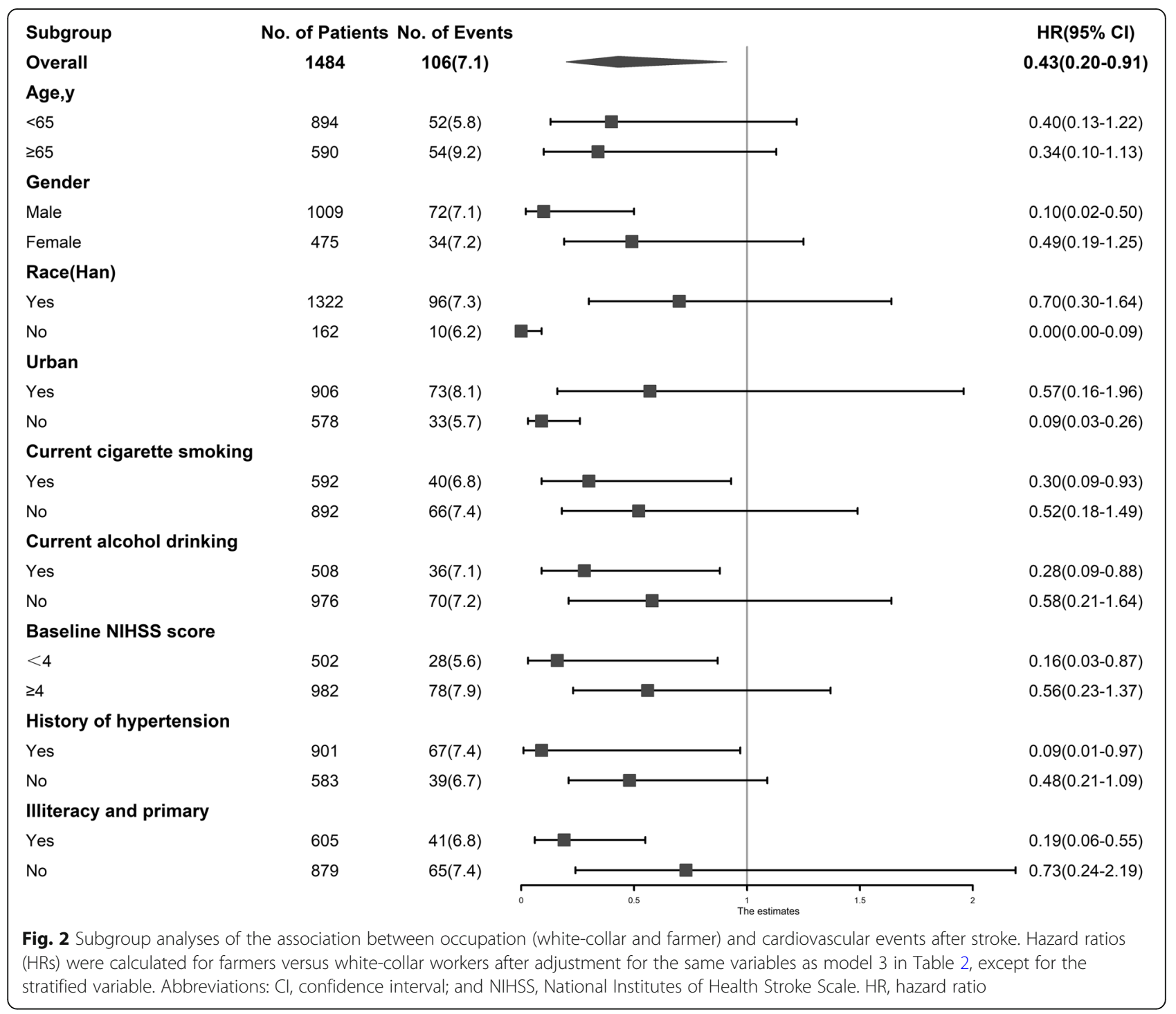


increase the risk of cardiovascular disease [36-38] Taken together, these findings are similar to our results that white-collars, who usually work long hours, experience less occupational physical activities, suffer from diabetes mellitus more and are exposed to high job strain with long-time sedentary behavior [39], have more risk factors of cardiovascular events.

With aging population and increasing prevalence of ischemic stroke, China is bearing almost biggest stroke burden around the world. Although low education, income and composite SES was associated with increased risk of stroke mortality both in Chinese and caucasians, the risk of stroke mortality in patients with low education, income, and occupation in Europe was lower than China [14, 40, 41]. This may be due to smaller socioeconomic inequalities and the disparities of work conditions (such as high job strain, insufficient occupational physical activities, work schedule and so on) $[25,30]$. Besides, multiple genetic factors and environmental exposure may contribute to this difference $[14,42]$.

Over the past few decades, China has undergone rapid improvement in economic and society with demographic transitions and lifestyle changes, as well as occupational composition alteration. However, there was recognized inequality between different occupation in China due to disparities in education, rural-urban residence, income, social welfare and healthcare services [40, 43-45]. Therefore, we are supposed to pay more attention to occupational difference in stroke patients. Correspondingly, preventive interventions of health promotion targeting people at high risk occupational groups would be helpful in campaigns to reduce stroke incidence and improve the prognosis. Additionally, occupational therapy, which is referred to the therapeutic use of work, self-care, and playing activities to improve occupational performance and social participation, can be a good choice for those suitable population [46, 47].

The strengths of our study included rigid quality control and relatively comprehensive data collection. Previous studies mainly paid attention to the association between occupational class and stroke incidence [22, 27, $31,43,48]$, while our study was concerned about various short-term ischemic stroke outcomes. Nevertheless, certain limitations should be noted. First, the incidence of cardiovascular events in our study during 12-month follow-up is relatively low [3]. However, in our study, the median NIHSS score was 5 (interquartile range, 3-8) at baseline and 3 (interquartile range, 1-6) at discharge, most patients had a lower NIHSS, which means the majority of participants had mild stroke. In addition, our participants had received good secondary prevention during hospitalization. Therefore, the incidence of cardiovascular events was relatively lower. Second, homemakers and freelance were excluded due to limited numbers and patients included were all from China, thereby affecting external generalizability. Further work is urgently required to incorporate bigger sample size and more occupational classes. Third, residual confounding is inevitable in spite of adjustment for main potential confounders in analysis. For example, we did not collect the data, such as household income, working hours, occupational physical activities and mental health which may influence the difference between occupational groups, especially among those patients in low and middle income countries [30]. Besides, rehabilitation after discharge, an important indicator to assess the outcome of stroke, was not included in this study. Furthermore, to some extent, the data was out-of-date, which makes it cautious to generate the findings to today's patients. Thus, there is need of further studies with larger size to examine the relationship between more occupational groups and short-term and long-term outcomes of stroke in China.

\section{Conclusion}

In a word, farmers were associated with less risk of cardiovascular events within 12 months after ischemic stroke, compared with white-collar workers. Further prospective studies should be conducted among different occupational populations to improve our findings.

\section{Abbreviations}

IIPAIS: Infectious Factors, Inflammatory Markers, and Prognosis of Acute Ischemic Stroke; Cls: Confidence intervals; NIHSS: National Institutes of Health Stroke Scale; TOAST: Trial of Org 10,172 in Acute Stroke Treatment; BP: Blood pressure; SD: standard deviation; IQR: median with interquartile range; MoCA: Montreal Cognitive Assessment; HRs: Hazard ratios; PY: Person year; OR: Odds ratio; UK: United Kingdom

\section{Acknowledgements}

We express appreciation to the study participants and their relatives and the clinical staff at all participating hospitals for their support and contribution to this project.

\section{Authors' contributions}

Yonghong Zhang, Tan Xu and Chongke Zhong designed the study and wrote the protocol. Mo Zhou, Ping Huang, Peipei Zhang, Yumei Guo and Liying Lv collected and researched data. Yinwei Zhu and Yaling Lu managed the literature searches and analyses, and wrote the first draft of the manuscript. The author(s) read and approved the final manuscript.

\section{Funding}

This work was supported by the National Natural Science Foundation of China (grant: 81773522 and 81172760).

\section{Availability of data and materials}

The datasets used and analyzed during the current study are available from the corresponding author on reasonable request.

\section{Declarations}

\section{Ethics approval and consent to participate}

This study protocol was approved by the institutional review boards at Tulane University in the United States and Soochow University in China. All patients engaged in the research provided written informed consents. All methods were carried out in accordance with relevant guidelines and regulations. 


\section{Consent for publication}

Not applicable.

\section{Competing interests}

The authors declare that they have no competing interests.

\section{Author details}

'Department of Epidemiology, School of Public Health and Jiangsu Key Laboratory of Preventive and Translational Medicine for Geriatric Diseases, Medical College of Soochow University, 199 Renai Road, Industrial Park District, Suzhou, Jiangsu Province 215123, People's Republic of China. ${ }^{2}$ Department of Science and Research, The Affiliated Suzhou hospital of Nanjing Medical University, Suzhou, Jiangsu, People's Republic of China. ${ }^{3}$ Medical Records Room, Changzhou Traditional Chinese Medicine Hospital, Changzhou, Jiangsu, People's Republic of China. ${ }^{4}$ Department of Acute Infectious Disease Control and Prevention, Changzhou Center for Disease Control and Prevention, Changzhou, Jiangsu, People's Republic of China. ${ }^{5}$ Clinical Laboratory, Inner Mongolia Xingan League People's Hospital, Xingan League, Inner Mongolia, People's Republic of China.

\section{Received: 3 March 2021 Accepted: 29 June 2021}

Published online: 19 August 2021

\section{References}

1. Vos T, Lim SS, Abbafati C, Abbas KM, Abbasi M, Abbasifard M, et al. Global burden of 369 diseases and injuries in 204 countries and territories, 19902019: a systematic analysis for the global burden of disease study 2019. Lancet. 2020;396(10258):1204-22. https://doi.org/10.1016/S0140-6736(20)3 0925-9.

2. Wang Y-J, Li Z-X, Gu H-Q, Zhai Y, Jiang Y, Zhao X-Q, et al. China Stroke Statistics 2019: A Report From the National Center for Healthcare Quality Management in Neurological Diseases, China National Clinical Research Center for Neurological Diseases, the Chinese Stroke Association, National Center for Chronic and Non-communicable Disease Control and Prevention, Chinese Center for Disease Control and Prevention and Institute for Global Neuroscience and Stroke Collaborations. Stroke Vasc Neurol. 2020;5(3):21139.

3. Chen Y, Wright N, Guo Y, Turnbull I, Kartsonaki C, Yang L, et al. Mortality and recurrent vascular events after first incident stroke: a 9-year communitybased study of 0.5 million Chinese adults. Lancet Glob Health. 2020;8(4): e580-90. https://doi.org/10.1016/S2214-109X(20)30069-3.

4. Marshall IJ, Wang Y, Crichton S, McKevitt C, Rudd AG, Wolfe CDA. The effects of socioeconomic status on stroke risk and outcomes. Lancet Neurol. 2015;14(12):1206-18. https://doi.org/10.1016/S1474-4422(15)00200-8.

5. Adler NE, Ostrove JM. Socioeconomic status and health: what we know and what we don't. Ann N Y Acad Sci. 1999;896(1):3-15. https://doi.org/10.1111/ j.1749-6632.1999.tb08101.x.

6. Abboud H, Labreuche J, Arauz A, Bryer A, Lavados PG, Massaro A, et al. Demographics, socio-economic characteristics, and risk factor prevalence in patients with non-cardioembolic ischaemic stroke in low- and middleincome countries: the OPTIC registry. Int J Stroke. 2013;8(Suppl A100):4-13.

7. Amarenco P, Abboud H, Labreuche J, Arauz A, Bryer A, Lavados PM, et al. Impact of living and socioeconomic characteristics on cardiovascular risk in ischemic stroke patients. Int J Stroke. 2014;9(8):1065-72. https://doi.org/1 0.1111/ijs.12290.

8. Scott SB, Graham-Engeland JE, Engeland CG, Smyth JM, Almeida DM, Katz $\mathrm{MJ}$, et al. The effects of stress on cognitive aging, physiology and emotion (ESCAPE) project. BMC Psychiatry. 2015;15(1):146. https://doi.org/10.1186/s12 888-015-0497-7.

9. Dong L, Eaton WW, Spira AP, Agnew J, Surkan PJ, Mojtabai R. Job strain and cognitive change: the Baltimore epidemiologic catchment area follow-up study. Occup Environ Med. 2018;75(12):856-62. https://doi.org/10.1136/ oemed-2018-105213.

10. Eyles E, Manley D, Jones K. Occupied with classification: which occupational classification scheme better predicts health outcomes? Soc Sci Med. 2019; 227:56-62. https://doi.org/10.1016/j.socscimed.2018.09.020.

11. Havranek EP, Mujahid MS, Barr DA, Blair IV, Cohen MS, Cruz-Flores S, et al. Social determinants of risk and outcomes for cardiovascular disease: a scientific statement from the American Heart Association. Circulation. 2015; 132(9):873-98. https://doi.org/10.1161/CIR.0000000000000228.
12. Magkos F, Hjorth MF, Astrup A. Diet and exercise in the prevention and treatment of type 2 diabetes mellitus. Nat Rev Endocrinol. 2020;16(10):54555. https://doi.org/10.1038/s41574-020-0381-5.

13. Zhang Y, Pan XF, Chen J, Xia L, Cao A, Zhang Y, et al. Combined lifestyle factors and risk of incident type 2 diabetes and prognosis among individuals with type 2 diabetes: a systematic review and meta-analysis of prospective cohort studies. Diabetologia. 2020;63(1):21-33. https://doi.org/1 0.1007/s00125-019-04985-9.

14. Wang S, Zhai H, Wei L, Shen B, Wang J. Socioeconomic status predicts the risk of stroke death: a systematic review and meta-analysis. Prev Med Rep. 2020;19:101124. https://doi.org/10.1016/j.pmedr.2020.101124

15. Langagergaard V, Palnum KH, Mehnert F, Ingeman A, Krogh BR, Bartels P, et al. Socioeconomic differences in quality of care and clinical outcome after stroke: a nationwide population-based study. Stroke. 2011;42(10):2896902. https://doi.org/10.1161/STROKEAHA.110.611871.

16. Arrich J, Lalouschek W, Mullner M. Influence of socioeconomic status on mortality after stroke - retrospective cohort study. Stroke. 2005;36(2):310-4. https://doi.org/10.1161/01.STR.0000152962.92621.b5.

17. Chen R, Hu Z, Chen RL, Zhang D, Xu L, Wang J, et al. Socioeconomic deprivation and survival after stroke in China: a systematic literature review and a new population-based cohort study. BMJ Open. 2015;5(1):e005688. https://doi.org/10.1136/bmjopen-2014-005688.

18. Pennlert J, Asplund K, Glader EL, Norrving B, Eriksson M. Socioeconomic status and the risk of stroke recurrence: persisting gaps observed in a Nationwide Swedish study 2001 to 2012. Stroke. 2017;48(6):1518-23. https:// doi.org/10.1161/STROKEAHA.116.015643.

19. Guo D, Zhu Z, Xu T, Zhong C, Wang A, Xie X, et al. Plasma S100A8/A9 concentrations and clinical outcomes of ischemic stroke in 2 independent multicenter cohorts. Clin Chem. 2020;66(5):706-17. https://doi.org/10.1093/ clinchem/hvaa069.

20. Adams HP Jr, Bendixen BH, Kappelle LJ, Biller J, Love BB, Gordon DL, et al. Classification of subtype of acute ischemic stroke. Definitions for use in a multicenter clinical trial. TOAST. Trial of org 10172 in acute stroke treatment. Stroke. 1993;24(1):35-41. https://doi.org/10.1161/01.STR.24.1.35.

21. Pickering TG, Hall JE, Appel LJ, Falkner BE, Graves JW, Hill MN, et al. Recommendations for blood pressure measurement in humans: an AHA scientific statement from the council on high blood pressure research professional and public education subcommittee. J Clin Hypertens (Greenwich). 2005;7(2):102-9. https://doi.org/10.1111/j.1524-6175.2005.04377.X.

22. $\mathrm{Xu}$ F, Ah Tse L, Yin $\mathrm{X}, \mathrm{Yu}$ IT, Griffiths $\mathrm{S}$. Impact of socio-economic factors on stroke prevalence among urban and rural residents in mainland China. BMC Public Health. 2008;8(1):170. https://doi.org/10.1186/1471-2458-8-170.

23. Galobardes B, Shaw M, Lawlor DA, Lynch JW, Davey Smith G. Indicators of socioeconomic position (part 2). J Epidemiol Community Health. 2006;60(2): 95-101. https://doi.org/10.1136/jech.2004.028092.

24. McFadden E, Luben R, Wareham N, Bingham S, Khaw KT. Social class, risk factors, and stroke incidence in men and women: a prospective study in the European prospective investigation into cancer in Norfolk cohort. Stroke. 2009:40(4):1070-7. https://doi.org/10.1161/STROKEAHA.108.533414.

25. Zaitsu M, Kato S, Kim Y, Takeuchi T, Sato Y, Kobayashi Y, et al. Occupational Class and Risk of Cardiovascular Disease Incidence in Japan: Nationwide, Multicenter, Hospital-Based Case-Control Study. J Am Heart Assoc. 2019;8(6):e011350.

26. Becher H, Palm F, Aigner A, Safer A, Urbanek C, Buggle F, et al. Socioeconomic conditions in childhood, adolescence, and adulthood and the risk of ischemic stroke. Stroke. 2016;47(1):173-9.

27. Novak M, Toren K, Lappas G, Kok WG, Jern C, Wilhelmsen L, et al. Occupational status and incidences of ischemic and hemorrhagic stroke in Swedish men: a population-based 35-year prospective follow-up study. Eur J Epidemiol. 2013;28(8):697-704. https://doi.org/10.1007/s10654-013-9833-8.

28. Kivimaki M, Lawlor DA, Davey Smith G, Kouvonen A, Virtanen M, Elovainio $\mathrm{M}$, et al. Socioeconomic position, co-occurrence of behavior-related risk factors, and coronary heart disease: the Finnish public sector study. Am J Public Health. 2007;97(5):874-9. https://doi.org/10.2105/AJPH.2005.078691.

29. Schnall P, Belkic K, Landsbergis P, Baker D. Why the workplace and cardiovascular disease? Occup Med. 2000;15(1):1-6 iii.

30. Bennett DA, Du H, Clarke R, Guo Y, Yang L, Bian Z, et al. Association of Physical Activity with Risk of major cardiovascular diseases in Chinese men and women. JAMA Cardiol. 2017:2(12):1349-58. https://doi.org/10.1001/jamacardio.2017.4069.

31. Kumar A, Prasad M, Kathuria P. Sitting occupations are an independent risk factor for ischemic stroke in north Indian population. Int J Neurosci. 2014; 124(10):748-54. https://doi.org/10.3109/00207454.2013.879130. 
32. Yu L, Liang Q, Zhou W, Huang X, Hu L, You C, et al. Sedentary behavior and the risk of cardiac-cerebral vascular diseases in southern China. Medicine (Baltimore). 2018;97(44):e12838. https://doi.org/10.1097/MD.0000000000012 838.

33. Fadel M, Sembajwe G, Gagliardi D, Pico F, Li J, Ozguler A, et al. Association between reported long working hours and history of stroke in the CONSTANCES cohort. Stroke. 2019;50(7):1879-82. https://doi.org/10.1161/ STROKEAHA.119.025454.

34. Dossa A, Glickman ME, Berlowitz D. Association between mental health conditions and rehospitalization, mortality, and functional outcomes in patients with stroke following inpatient rehabilitation. BMC Health Serv Res. 2011;11(1):311. https://doi.org/10.1186/1472-6963-11-311.

35. Liman TG, Heuschmann PU, Endres M, Floel A, Schwab S, Kolominsky-Rabas PL. Impact of low mini-mental status on health outcome up to 5 years after stroke: the Erlangen stroke project. J Neurol. 2012;259(6):1125-30. https:// doi.org/10.1007/s00415-011-6312-6.

36. Magnusson Hanson LL, Rod NH, Vahtera J, Peristera P, Pentti J, Rugulies R, et al. Multicohort study of change in job strain, poor mental health and incident cardiometabolic disease. Occup Environ Med. 2019;76(11):785-92. https://doi.org/10.1136/oemed-2018-105595.

37. Huang Y, Xu S, Hua J, Zhu D, Liu C, Hu Y, et al. Association between job strain and risk of incident stroke: a meta-analysis. Neurology. 2015:85(19): 1648-54. https://doi.org/10.1212/WNL.0000000000002098.

38. Fransson El, Nyberg ST, Heikkila K, Alfredsson L, Bjorner JB, Borritz M, et al. Job strain and the risk of stroke: an individual-participant data meta-analysis. Stroke. 2015:46(2):557-9. https://doi.org/10.1161/STROKEAHA.114.008019.

39. Tsutsumi A, Kayaba K, Ishikawa S. Impact of occupational stress on stroke across occupational classes and genders. Soc Sci Med. 2011;72(10):1652-8. https://doi.org/10.1016/j.socscimed.2011.03.026.

40. Che B, Shen S, Zhu Z, Wang A, Xu T, Peng Y, et al. Education level and long-term mortality, recurrent stroke, and cardiovascular events in patients with ischemic stroke. J Am Heart Assoc. 2020;9(16):e016671. https://doi. org/10.1161/JAHA.120.016671.

41. Shin J, Choi Y, Kim SW, Lee SG, Park EC. Cross-level interaction between individual socioeconomic status and regional deprivation on overall survival after onset of ischemic stroke: national health insurance cohort sample data from 2002 to 2013. J Epidemiol. 2017;27(8):381-8. https://doi.org/10.1016/j. je.2016.08.020

42. Pulit SL, McArdle PF, Wong Q, Malik R, Gwinn K, Achterberg S, et al. Loci associated with ischaemic stroke and its subtypes (SiGN): a genome-wide association study. Lancet Neur. 2016;15(2):174-84. https://doi.org/10.1016/ S1474-4422(15)00338-5.

43. Zhou WJ, Chen RL, Hopkins A, Wang YL, Tang J, Chen XY, et al. Association between socioeconomic status and incident stroke in China. J Epidemiol Commun H. 2020;74(6):519-26.

44. Sicular T, Ximing Y, Gustafsson B, Shi L. The urban?Rural income gap and inequality in China. Rev Income Wealth. 2007;53(1):93-126. https://doi.org/1 0.1111/j.1475-4991.2007.00219x

45. Huang C, Liu CJ, Pan XF, Liu X, Li NX. Correlates of unequal access to preventive care in China: a multilevel analysis of national data from the 2011 China health and nutrition survey. BMC Health Serv Res. 2016;16(1): 177. https://doi.org/10.1186/s12913-016-1426-2.

46. Eroglu M, Karapolat H, Atamaz F, Tanigor G, Kirazli Y. Occupational therapy assessment and treatment approach in patients with subacute and chronic stroke: a single-blind, prospective, randomized clinical trial. Turk J Phys Med Rehabil. 2020;66(3):316-28. https://doi.org/10.5606/tftrd.2020.4321.

47. Legg LA, Lewis SR, Schofield-Robinson OJ, Drummond A, Langhorne P. Occupational therapy for adults with problems in activities of daily living after stroke. Cochrane Database Syst Rev. 2017:7:CD003585.

48. MacDonald LA, Bertke S, Hein MJ, Judd S, Baron S, Merritt R, et al. Prevalence of cardiovascular health by occupation: a cross-sectional analysis among US Workers aged $>=45$ years. Am J Prev Med. 2017;53(2):152-61. https://doi.org/10.1016/j.amepre.2017.02.022

\section{Publisher's Note}

Springer Nature remains neutral with regard to jurisdictional claims in published maps and institutional affiliations.

Ready to submit your research? Choose BMC and benefit from:

- fast, convenient online submission

- thorough peer review by experienced researchers in your field

- rapid publication on acceptance

- support for research data, including large and complex data types

- gold Open Access which fosters wider collaboration and increased citations

- maximum visibility for your research: over $100 \mathrm{M}$ website views per year

At BMC, research is always in progress.

Learn more biomedcentral.com/submissions 